\title{
Диагностика синдрома обструктивного апноэ во сне и первый опыт длительной СРАР-терапии в домашних условиях
}

ГОУ ВПО "Алтайский государственный медицинский университет Росздрава": 656038, Барнаул, пр-т Ленина, 40

\author{
Ya.N.Shoykhet, T.I.Martynenko, A.V.Markin
}

\section{The diagnosis of obstructive sleep apnea syndrome and the first experience of long-term respiratory support at home}

\begin{abstract}
Summary
The purpose of the study was to investigate prevalence of the obstructive sleep apnea (OSA) syndrome and efficacy of long-term respiratory support at home. The study was based on the data of 249 patients with sleep disorders ( 197 males, 52 females, age from 33 to 74 yrs). The prevalence of OSA in patients of a somnology centre was $86.4 \%$. In CPAP treated patients, the apnea / hypopnea index decreased from $55.4 \pm 5.9$ to $3.4 \pm 0.5$ ( $p<0.001)$, the daytime sleepiness (Epworth scale) decreased from $14.0 \pm 1.0$ до $2.2 \pm 0.2(p<0.001)$, the minimal nighttime $\mathrm{SaO}_{2}$ increased from $72.7 \pm 2.5 \%$ to $86.1 \pm 0.8 \%(p<0,001)$, mean nighttime $\mathrm{SaO}_{2}$ increased from $89.87 \pm 1.3 \%$ to $94.1 \pm 0.5 \%(p<0.01)$. In 6 months of CPAP therapy, the arterial blood pressure normalized in $68.8 \%$ of the patients, body mass decreased by $12.2 \mathrm{~kg}$ (range, from 2 to $25 \mathrm{~kg}$ ) in $63.6 \%$ of the patients. Thus, we have demonstrated significant prevalence the OSA in the somnology centre and positive effects CPAP-therapy on the airway obstructive disorders, nighttime $\mathrm{SaO}_{2}$, daytime sleepiness, body mass, and arterial pressure.

Key words: obstructive sleep apnea syndrome, CPAP, apnea / hypopnea index, oxygen saturation.
\end{abstract}

\section{Резюме}

Цель исследования - изучить распространенность синдрома обструктивного апноэ во сне (СОАС) и эффективность длительной респираторной поддержки в домашних условиях. Изучались данные 249 пациентов (197 мужчин и 52 женшин) с расстройствами сна в возрасте от 33 до 74 лет. Распространенность СОАС среди пациентов сомнологического центра составила 86,4 \%. В результате СРАР-терапии индекс апноэ / гипопноэ снизился с 55,4 $\pm 5,9$ до $3,4 \pm 0,5$ ( $p<0,001)$ а степень дневной сонливости по шкале Эпфорт - с $14,0 \pm 1,0$ до $2,2 \pm 0,2$ балла $(p<0,001)$. Отмечено повышение минимального уровня насыщения крови кислородом в ночной период с $72,7 \pm 2,5$ до $86,1 \pm 0,8 \%(p<0,001)$ и среднего уровня насыщения крови кислородом в ночной период с $89,8 \pm 1,3 \%$ до $94,1 \pm 0,5 \%(p<0,01)$. Через 6 мес. артериальное давление стабилизировалось у 68,8 \% больных, снизился вес в среднем на 12,2 кг (от 2 до 25 кг) у $63,6 \%$. Таким образом, продемонстрирована значительная распространенность СОАС среди пациентов сомнологического центра. Анализ отдаленных результатов СРАР-терапии показал не только нормализацию инструментальных показателей обструкции верхних дыхательных путей, но и существенную динамику снижения веса, дневной сонливости и стабилизации артериального давления у большинства пациентов. Ключевые слова: синдром обструктивного апноэ во сне, СРАР-терапия, индекс апноэ / гипопноэ, насыщение крови кислородом.

Синдром обструктивного апноэ во сне (СОАС) - это угрожающее жизни пациента дыхательное расстройство, определяемое как период асфиксии во время сна и приводящее к развитию избыточной дневной сонливости, гемодинамическим расстройствам и нестабильности сердечной деятельности [1]. Результаты крупных исследований, проведенных в США, Европе, Австралии и Азии, показали, что примерно у 1 из 5 взрослых лиц имеются инструментальные признаки СОАС легкой степени с индексом апноэ / гипопноэ (ИАГ) $\geq 5$, а у 1 из 15 - среднетяжелой или тяжелой СОАС (ИАГ $\geq 15)$ [2]. Полная клиническая картина заболевания встречается у $1-5 \%$ мужчин и 0,5-2,0\% женщин [3].

В настоящее время СОАС считается одним из существенных факторов риска развития артериальной гипертензии (АГ), острого нарушения мозгового кровообращения (ОНМК), нарушений ритма сердца, ишемии миокарда во время сна $[4,5]$.

Основными причинами осложнений со стороны системы кровообращения при СОАС являются ги- поксемия, дисбаланс между активностью парасимпатической и симпатической систем и процессы воспаления, включающие оксидативный стресс, гиперпродукцию оксида азота, С-реактивного протеина, интерлейкина-6, активацию тромбоцитов, развитие эндотелиальной дисфункции и атеросклероза [6].

По разным данным, летальность в течение больных СОАС 5 лет составляет 11-37 \% [7, 8]. Сосудистые нарушения стали причиной смерти $71 \%$ больных COAC, $1 / 2$ из которых умерли в ночное время [8].

Доказана связь между избыточной дневной сонливостью пациентов СОАС и дорожно-транспортными происшествиями (ДТП): 20 \% аварийных ситуаций возникают из-за засыпания за рулем. Среди пациентов с СОАС риск ДТП в 4-6 раз выше, чем у лиц в состоянии алкогольного опьянения [9].

Целью настоящего исследования явилось изучение распространенности СОАС и эффективности длительной респираторной поддержки в домашних условиях. 


\section{Материалы и методы}

Были изучены данные 249 пациентов (197 мужчин и 52 женщины) с расстройствами сна в возрасте от 33 до 74 лет, находившихся под наблюдением в Алтайском краевом пульмонологическом центре (Барнаул) в 2006-2008 гг.

Среди жалоб у наблюдаемых больных обращали на себя внимание остановка дыхания во сне, громкий или прерывистый храп, избыточная дневная сонливость, учащенное ночное мочеиспускание, длительное нарушение ночного сна, подъем артериального давления, особенно в ночные и утренние часы. Учитывалось наличие избыточного веса.

Наличие указаний на остановку дыхания во сне или сочетание любых 3 из указанных выше признаков служили показанием для инструментального обследования [10]. Проводились полисомнография (ПСГ) и кардиореспираторный мониторинг на оборудовании Embla N7000 (Medcare, США).

Целью ПСГ было определение вида и характера расстройств дыхания (обструктивный или центральный), регистрация ИАГ - количества эпизодов апноэ и гипопноэ в среднем за час. Изучались электроэнцефалограмма, электроокулограмма, электромиограмма, храп, дыхательный поток, насыщение крови кислородом, дыхательные движения грудной клетки и брюшной стенки, положение тела, движения нижних конечностей, а также осуществлялось видеонаблюдение. Определялась зависимость нарушений дыхания от положения тела и стадии сна, влияния на насыщение крови кислородом, ритм и проводимость сердца, структуру сна и развитие микроактиваций мозга (реакций arousal).

Чтобы оценить состояние слизистой оболочки ротоглотки и определить возможные причины обструкции верхних дыхательных путей, проводилась прямая фарингоскопия и эндоскопическая фиброринофаринголарингоскопия с помощью эндоскопа Olympus BF-P30 (Olympus Corporation, Япония).

В качестве базисной терапии СОАС использовалась СРАР-терапия - метод, основанный на создании непрерывного положительного давления в дыхательных путях (Continuous Positive Airway Pressure), подаваемого пациенту посредством носовых или носоротовых масок. Показанием для назначения СРАР-терапии были [11]:

1) индекс апноэ $\geq 20$ или ИАГ $\geq 30$ в час независимо от наличия или отсутствия клинических симптомов;

2) $5 \leq$ ИАГ < 30 до в час, если заболевание сопровождалось хотя бы одним из ниже перечисленных факторов: дневной сонливостью, нарушением памяти, психоэмоциональными расстройствами, бессонницей, документированными сердечнососудистыми поражениями (АГ, ишемической болезнью сердца (ИБС) или инсультом), нарушением сердечного ритма и проводимости, связанными с нарушениями дыхания во сне.

Назначение лечения требовало проведения пробной (тестовой) ночи для подбора параметров респи- раторной поддержки, в первую очередь уровня давления, и для оценки комплаентности больного. СРАР-терапия проводилась автоматическими посредством приборов Somnobalance (Weinmann, Германия) и AutoSet Spirit (ResMed, США).

\section{Результаты и обсуждение}

У всех наблюдаемых больных были показания для проведения инструментального обследования. Остановки дыхания во время сна имелись у 69 пациентов $(27,7 \%)$, громкий, прерывистый храп - у $215(86,4 \%)$, избыточная дневная сонливость - у 198 (79,5\%). Длительное нарушение ночного сна было выявлено у 200 человек (80,3\%), учащенное ночное мочеиспускание - у 145 (58,2 \%). Ночной и утренний подъем артериального давления регистрировался у 160 $(64,3 \%)$, избыточный вес - у 220 пациентов $(88,4 \%)$.

У $215(86,4 \%)$ из 249 обследованных был диагностирован СОАС. Из них у 92 больных $(42,8 \%)$ степень заболевания была тяжелой (ИАГ $\geq 40$ ), у 60 $(27,9 \%)-$ среднетяжелой (ИАГ $=20-39)$, у 63 $(29,3 \%)$ - легкой (ИАГ $=10-19)$.

У 200 (93,0 \%) больных СОАС была АГ, у 183 $(85,1 \%)$ - ожирение, у 86 (40,0 \%) - ИБС. В анамнезе у 65 пациентов $(30,2 \%)$ отмечены нарушения ритма сердца, у $26(12,1 \%)$ - острый инфаркт миокарда, у $19(8,8 \%)$ - ОНМК (рис. 1$)$.

У всех пациентов из-за ожирения глоточное кольцо было сужено, имелись признаки хронического воспаления слизистой, травмируемой при храпе (отек, гиперемия или цианоз), или другие изменения, например резко гипертрофированные миндалины, подтверждающие возможность обструкции верхних дыхательных путей во время сна (рис. 2).

У 8 (3,2\%) больных с целью локализации уровня обструкции верхних дыхательных путей выполнялась эндоскопическая фиброринофаринголарингоскопия (рис. 3).

У $172(80,0 \%)$ больных СОАС имелись показания для СРАР-терапии. Это были 92 (42,8 \%) пациента с тяжелой формой СОАС, 60 (27,9\%) - со средней и $20(9,3 \%)-$ с легкой. Им проводилось тестирование респираторной поддержки. Курсовое лечение аппаратным методом в течение 3-20 сут. получил 131 пациент $(60,9 \%)$ с СОАС. У 38 человек $(17,6 \%)$ курсовое лечение не проводилось в связи с низкой комплаентностью. Из них у $18(8,4 \%)$ была легкая

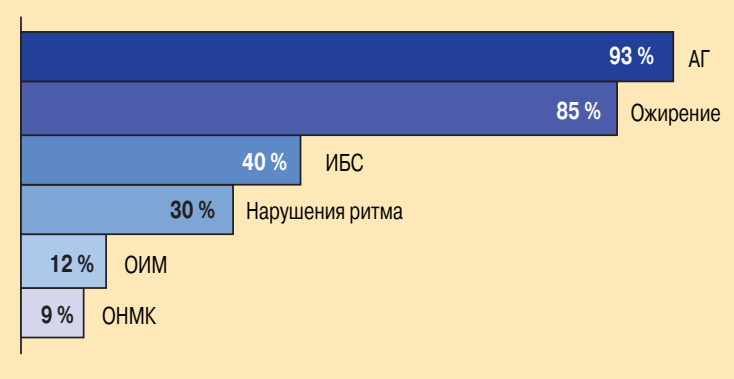

Рис. 1 . Сопутствующие заболевания у больных СОАС $(n=215)$ 

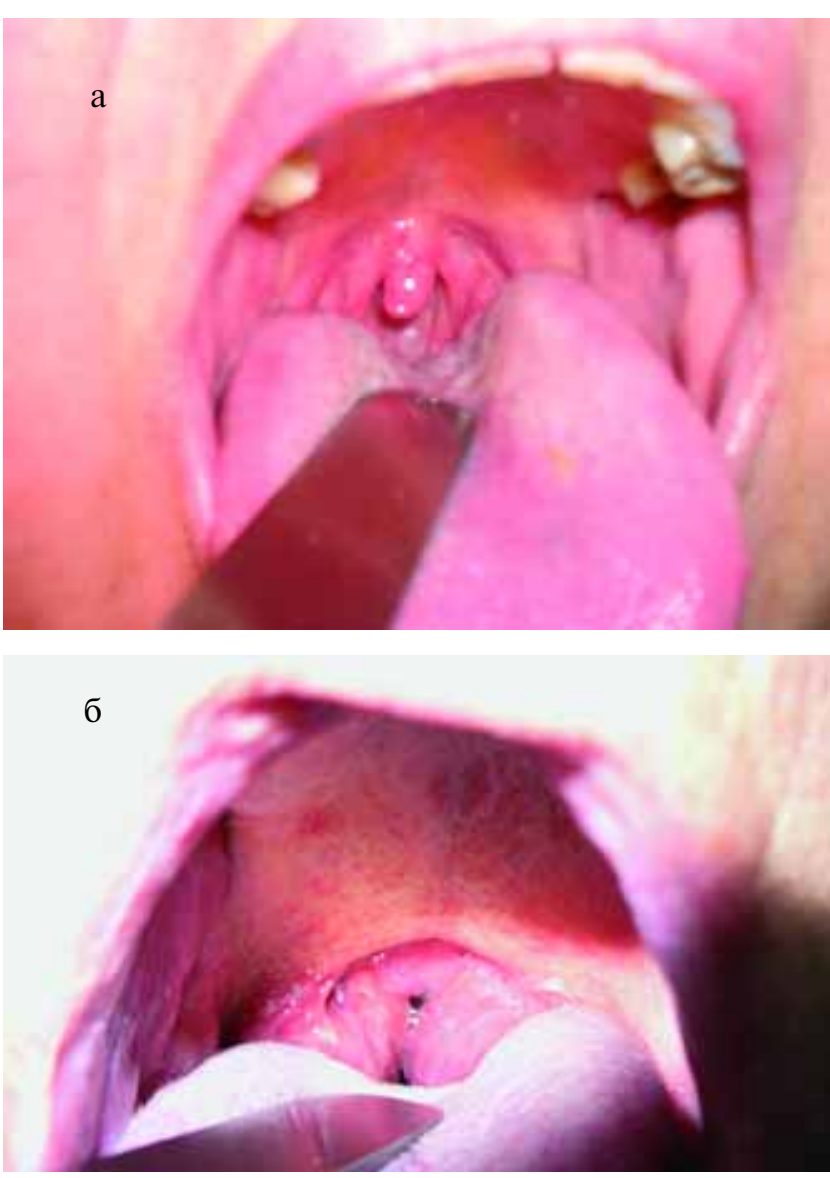

Рис. 2. Глоточное кольцо при ожирении (а) и выраженной гипертрофии миндалин (б)

степень тяжести СОАС, у 3 (1,4 \%) - непереносимость маски. Длительная СРАР-терапия в домашних условиях проводилась 25 пациентам (11,6 \%) в течение 2-36 мес. Полугодовой рубеж лечения преодолели 22 человека (10,2 \%) с СОАС (20 мужчин, 2 женщины в возрасте от 36 до 76 лет с ИАГ от 11 до 105,4).

На фоне длительной СРАР-терапии ИАГ снизился с 55,4 \pm 5,9 до 3,4 \pm 0,5 ( $p<0,001)$, а степень дневной сонливости по шкале Эпфорт (ESS) - с 14,0 \pm 1,0 до 2,2 $\pm 0,2$ балла $(p<0,001)$, как показано на рис. 4. Произошло повышение минимального уровня насыщения крови кислородом $\left(\mathrm{SaO}_{2 \min }\right)$ в ночной период с 72,7 $\pm 2,5$ до 86,1 $\pm 0,8 \%(p<0,001)$ и среднего уровня насыщения крови кислородом $\left(\mathrm{SaO}_{2 \text { средн. }}\right)$ в ночной период с 89,8 $\pm 1,3$ до 94, $1 \pm 0,5 \%(p<0,01)$, как показано на рис. 5.

В результате длительной СРАР-терапии в домашних условиях через 6 мес. стабилизация артериального давления произошла у 15 (68,8 \%) из 22 пациентов, снижение веса на 12,2 \pm 6,6 кг (от 2 до 25 кг) у 14 больных $(63,6 \%)$.

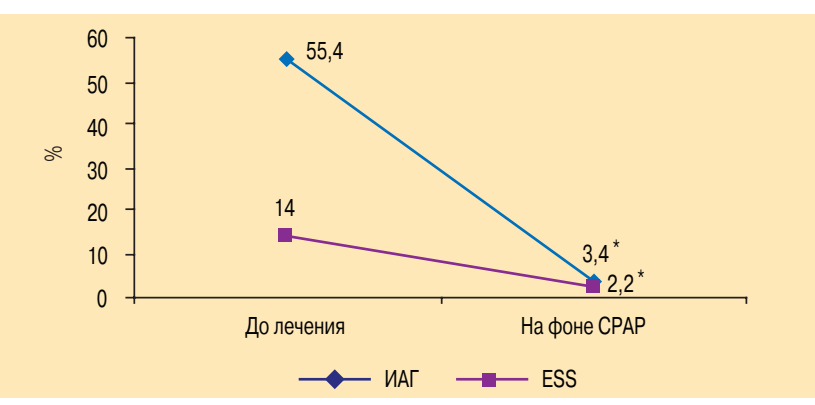

Рис. 4. Динамика ИАГ и дневной сонливости на фоне СРАР-терапии Примечание: ${ }^{*}-p<0,001$.

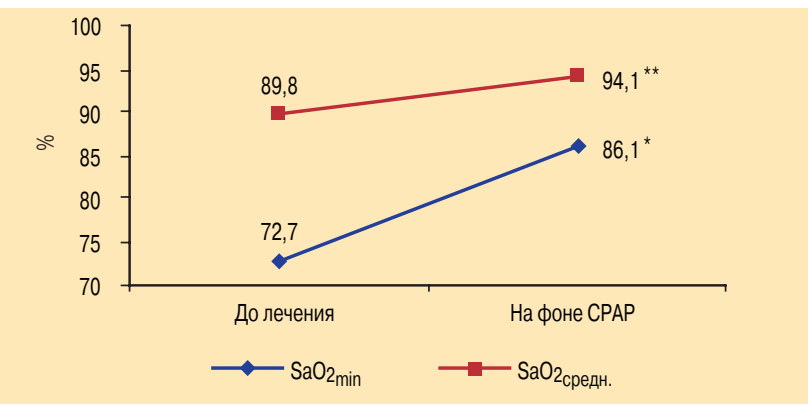

Рис. 5. Динамика минимального и среднего уровня ночной $\mathrm{SaO}_{2}$ на фоне СРАР-терапии

Примечание: ${ }^{*}-p<0,001 ;{ }^{* *}-p<0,01$.

При самооценке пациентами результата лечения 11 человек (50,0 \%) обозначили его как "отличный", $10(45,5 \%)$ - "хороший", 1 (4,5 \%) - "удовлетворительный".

\section{Заключение}

Распространенность СОАС среди пациентов сомнологического центра составила $86,4 \%$. В результате СРАР-терапии в течение 6 мес. произошла стабилизация артериального давления у 68,8 \% больных и снижение веса на 12,2 кг у 63,6 \% пациентов. На фоне лечения уменьшились ИАГ в 16,3 раза $(p<0,001)$, степень дневной сонливости - в 6,4 раза $(p<0,001)$. Отмечено повышение минимального и среднего уровня $\mathrm{SaO}_{2}$ в ночной период на $13,4 \%(p<0,001)$ и 4,3\% $(p<0,01)$ соответственно.

\section{Литература}

1. Guilleminault $C$., Dement $W$. Sleep apnea syndromes and related sleep disorders. Sleep disorders: Diagnosis and treatment. New York: Wiley; 1978. 9-28.

2. Somers V., White D., Raouf Amin et al. Sleep apnea and cardiovascular disease. AHA / ACCF Scientific Statement. Circulation 2008; 118: 1080-1111.

3. Parati G., Lombardi C., Narkiewicz K. Sleep apnea: epidemiology, pathophysiology, and relation to cardiovascular

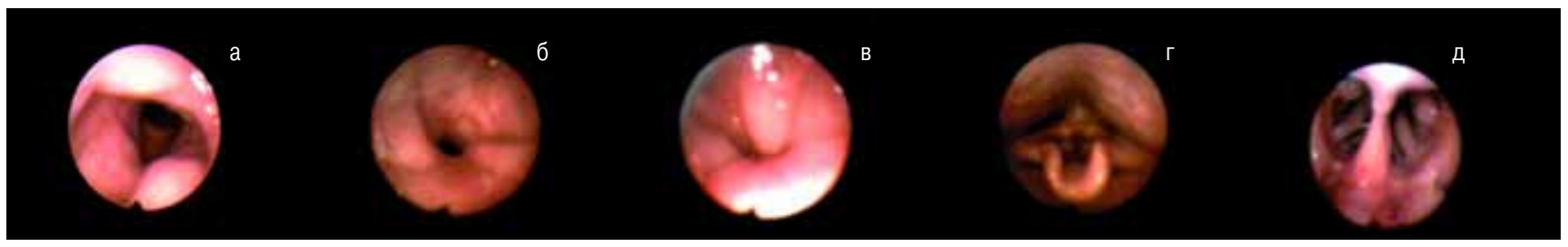

Рис. 3. Различная степень обструкции верхних дыхательных путей на уровне ротоглотки (а-в) при отсутствии патологии со стороны надгортанника, голосовых связок (г) и носоглотки (д) 
risk. Am. J. Physiol. Regul. Integr. Comp. Physiol. 2007; 293: 1671-1683.

4. Вейн А.М., Елигулашвили Т.С., Полуэктов М.Г. Синдром апноэ во сне. М.: Эйдос Медиа; 2002.

5. Valham F., Mooe Th., Rabben T. et al. Increased risk of stroke in patients with coronary artery disease and sleep apnea. A 10-year follow-up. Circulation 2008; 118: 955-960.

6. Литвин А.Ю, Чазова И.Е. Синдром обструктивного апноэ во время сна и связанные с ним сердечно-сосудистые осложнения (обзор). Кардиология СНГ 2006; IV: 96-110.

7. Partien M., Jameison A., Guilleminault C. Long-term outcome for obstructive sleep apnea patients; mortality. Chest 1988; 94 (1): 1200-1204.

8. Thorpy M., Ledereich P., Burack B. Death in patients with obstructive sleep apnea. Sleep Res. 1990; 19: 301.

9. George $C$. Driving and automobile crashes in patients with obstructive sleep apnoea / hypopnoea syndrome. Thorax 2004; 59: 804-807.
10. Бузунов Р.В., Ерошина В.А., Легейда И.В. Храп и синдром обструктивного апноэ сна: Учеб. пособие для врачей. М.; 2007.

11. Loube D.I., Gay P.C., Strohl K.P. et al. Indications for positive airway pressure treatment of adult obstructive sleep apnea patients: a consensus statement. Chest 1999; 115: 963-866.

\section{Информация об авторах}

Шойхет Яков Нахманович - член-корр. РАМН, д. М. н., проф., зав. кафедрой факультетской хирургии с курсом хирургии ФУВ им. И.И.Неймарка Алтайского государственного медицинского университета; тел.: (3852) 68-50-23

Мартыненко Татьяна Ивановна - д. м. н., проф. кафедры терапии и семейной медицины ФУВ с курсом клинической иммунологии и аллергологии Алтайского государственного медицинского университета; тел.: (3852) 68-85-12; e-mail: rtppul@ab.ru

Маркин Алексей Вячеславович - к. М. н., докторант кафедры факультетской хирургии с курсом хирургии ФУВ им. И.И.Неймарка Алтайского государственного медицинского университета; тел.: (3852) 25-22-21; e-mail: markinal@inbox.ru

Поступила 25.05.09 () Коллектив авторов, 2009 УДК 616.24-008.444-085 